\title{
ELECTRICITY CONSUMPTION MEASUREMENT SYSTEM USING ESP32
}

\author{
A.C. Gheorghe ${ }^{1}$, E.Stan ${ }^{2}$, I.Udroiu ${ }^{2}$ \\ Valahia University of Targoviste, Faculty of Electrical Engineering, Electronics and Information Technology \\ E-mail: gheorghe_andrei89@yahoo.com
}

\begin{abstract}
The paper proposes the development of an IoT measurement system that offers the user the possibility to monitor and record the electricity consumed by a consumer through the Blynk application. In monitoring electricity one of its most important aspects is the calibration of the sensors used. Accurate and reliable detection is the key factor in measuring and managing electrical equipment. Fundamental physical quantities such as voltage and current are useful for determining all other electrical quantities. The ESP32 development board used to develop the system has 18 channels ADC (analog to digital converter) and supports a $\mathrm{Wi}-\mathrm{Fi}$ connection at the access point and implicitly to the internet. The developed system can measure the voltage (U), current (I), power consumption $(W)$ and consumption / hour $(\mathrm{kWh})$ of a consumer, in my case for the consumer I used a light bulb with a power given by the manufacturer of $10 \mathrm{~W}$. The measured values are displayed on the LCD display of the system or through the Blynk application which also allows the registration of these values for a period of 12 months.
\end{abstract}

Keywords: IoT, energy measurement, ESP32, Blynk

\section{INTRODUCTION}

The main units of an electrical system are represented by their voltage and current, so obtaining accurate measurements are very important when it comes to monitoring electrical load. This electrical monitoring is very important to facilitate energy management being one of the important factors when it comes to the sustainability of the system that has the role of energy supply by streamlining it and eliminating unwanted activities. As technology advances in terms of energy use and day-today processes become more and more automatic and intelligent, the part that deals with the precise and correct measurement of electricity becomes indispensable. To ensure the future of the electrical system, a precise measurement and monitoring is required for energy efficiency in the use of electricity [1].

The paper proposes the development of an IoT measurement system that offers the user the possibility to monitor and record the electricity consumed by a consumer through the Blynk application. The system developed is an economical solution for implementing such a system in a smart home environment.

When it comes to energy monitoring, the key element of this process is sensor calibration. Accurate and reliable detection is the key factor in measuring and managing electrical equipment [3]. Fundamental physical quantities such as voltage and current are useful for determining all other electrical quantities. Sensors dedicated specifically for this purpose are used to detect current and voltage, which can be found in many forms. Many models of current sensors such as ACS712, ACS716 and ACS756 already come calibrated and with a sensitivity offered by the manufacturer. These sensors allow the ADC value of the sensor to be converted using the calibration and sensitivity provided by the manufacturer. The ZMPT101B voltage sensor used for this system has a potentiometer that can be calibrated by the user, it should be mentioned, its calibration can be performed also from the software program. The SCT-013-030 current sensor used in the system is able to measure the current of a consumer up to $30 \mathrm{~A}$ and can also be calibrated by the software program [2].

The ESP32 development board used for the development of the system has 18 channels ADC (analog to digital converter) and supports a Wi-Fi connection at the access point and implicitly to the internet. The developed system can measure the voltage (U), current (I), power consumption (W) and consumption / hour $(\mathrm{kWh})$ of a consumer, in our case for the consumer we used a light bulb with a power given by the manufacturer of $10 \mathrm{~W}$. The measured values are displayed on the LCD display of the system or through the Blynk application that allows the recording of these values for a period of 12 months.

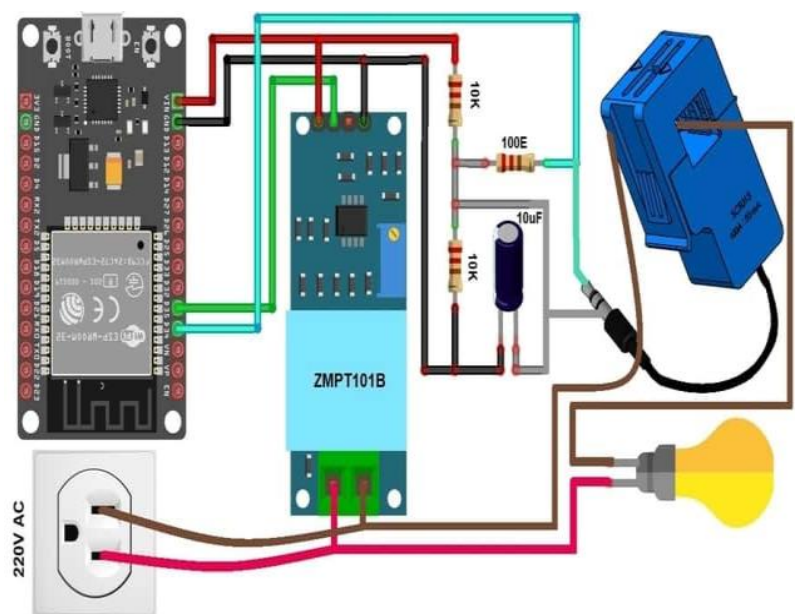

Figure 1. Measurement system circuit diagram.

The circuit diagram for the measurement system is shown in Figure 1. The ESP32 development board uses the D35 pin to connect to the ZMPT101B voltage sensor and the D34 pin to connect to SCT-013-030 current sensor. Pins D35 and D34 are 2 of 18 ADC channels provided by the ESP32 development board. Both the sensors are powered from a $+5 \mathrm{~V}$ power supply provided by the ESP32 VIN pin. An USB connection is need to power the ESP32 development board thus powering the whole system. The 
USB connection is also used to program the ESP32. For measuring the current and voltage of the consumer used, the voltage sensor is connected to the $\mathrm{L}$ and $\mathrm{N}$ lines from the A.C power supply used to power the light bulb and the current sensor si connected on the $\mathrm{N}$ line of the light bulb.

\section{HARDWARE DESCRIPTION}

\subsection{ESP32 development board}

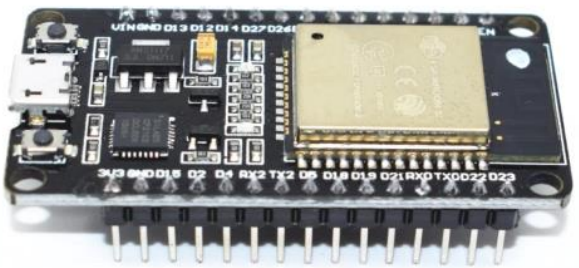

Figure 2. ESP32 development board.

The ESP32 microcontroller (Figure 2) is developed by Espressif System and is a SoC (System on Chip) type microcontroller. This microcontroller is the successor to the ESP8266 and is available for sale in single core and dual core variants. The microprocessor used for the ESP32 microcontroller is called Tensilica Extensa LX6, this microprocessor has a 32-bit architecture and comes with integrated technologies such as $\mathrm{Wi}-\mathrm{Fi}$ and Bluetooth. The Tensilica Extensa LX6 microprocessor is manufactured using a $40 \mathrm{~nm}$ technology which makes this processor efficient with a very low power consumption and this facilitates the development of applications that are powered by batteries. The microcontroller also has integrated RF components, among these components are a power amplifier, a reception amplifier, an antenna switch and filters. For a hardware design around the ESP32 microcontroller, few external components are needed.

\section{ESP32 specifications:}

- 520 KB SRAM memory

- 448 KB ROM memory

- $\quad 16$ KB RTC SRAM memory

- Connectivity: Wi-Fi 802.11 b/g/n, Bluetooth 4.2

- $\quad$ GPIO pins: 34

- 12-bit ADC SAR: 18

- 8-bit DAC: 2

- Serial connectivity: SPI, I2C, I2S, UART

- PWM pins: 16

Programming environments that are used:

- $\quad$ Arduino IDE

- PlatformIO IDE
- MicroPython

The Arduino IDE is used for the programing of the system because is already a familiar environment.

\subsection{ZMPT101B voltage sensor}

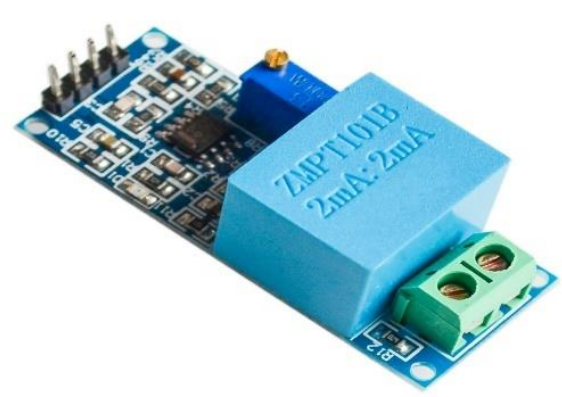

Figure 3. ZMPT101B voltage sensor.

ZMPT101B is a sensor used to measure alternating current voltage. This sensor uses an ideal voltage transformer for measurement. The sensor is very accurate for measuring voltage and power. The maximum voltage that the sensor can measures is $250 \mathrm{~V}$ A.C and comes with a variable potentiometer to calibrate the ADC output. The ZMPT101B sensor comes with a potentiometer that is used to adjust the ADC output for calibrating purposes.

\section{ZMPT101B specifications:}

- Voltage transformer that has micro-precision capabilities

- Op-amp circuit that has high precision

- Operating temperature: $-40^{\circ} \mathrm{C} \sim 70^{\circ} \mathrm{C}$

- Operating voltage: $5 \mathrm{~V}-30 \mathrm{~V}$ D.C

\subsection{SCT-013-030 current sensor}

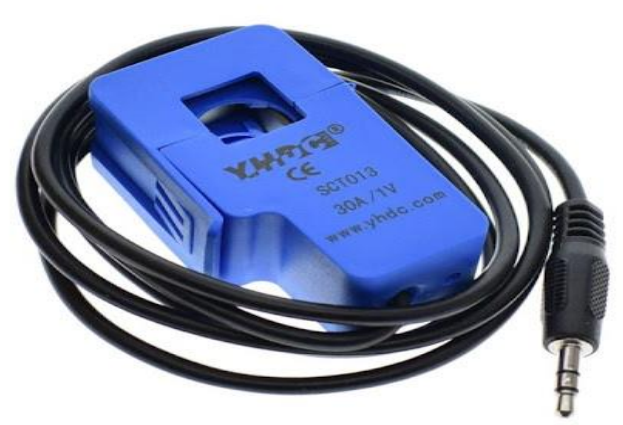

Figure 4. SCT-013-030 current sensor. 
The SCT-013-030 sensor is a non-invasive current sensor that is used to measure the intensity of a current flowing through a conductor without the need to cut or modify it. We use this sensor with the ESP32 development board to measure the intensity consumed by the light bulb.

\section{SCT-013-00 specifications:}

- $\quad$ Measured current: 0A - 30A

- Output voltage: $0 \mathrm{~V}-1 \mathrm{~V}$

- Accuracy: $\pm 1 \%$

- Linearity: $\leq 0.2 \%$

- Work voltage: $660 \mathrm{~V}$ A.C

- Work frequency: $50-1 \mathrm{KHz}$

- Operating temperature: $-25^{\circ} \mathrm{C} \sim+75^{\circ} \mathrm{C}$

- Dielectric voltage $50 \mathrm{~Hz} / 1$ minute: $3 \mathrm{KV}$

\section{MEASUREMENT SYSTEM PROGRAM AND BLYNK APPLICATION}

\subsection{Energy measuring code}

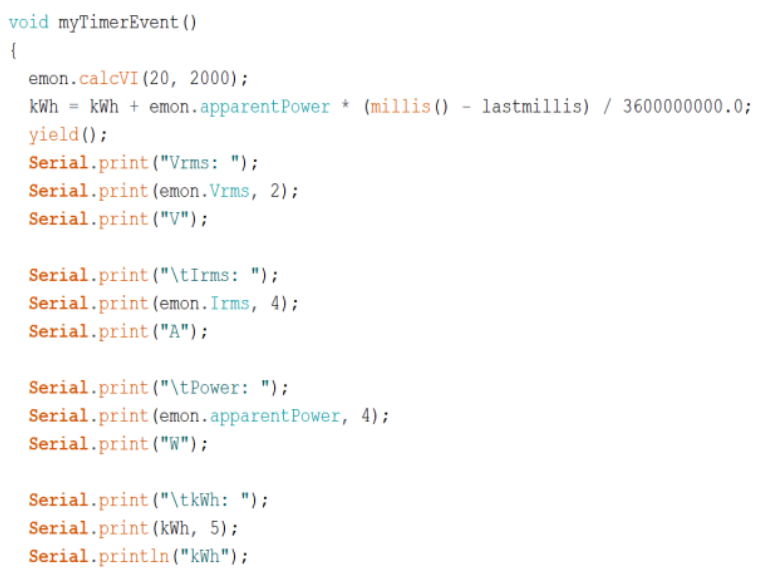

Figure 5. Energy measuring code.

For the energy measuring code shown in Figure 5 we have used the Emon library which contains the energy measuring functions for measuring the voltage, current, power and power consumption of our electrical consumer. This library uses the function "emon.Vrms" to measure the voltage data provided by the voltage sensor on pin 35 of the development board, "emon.Irms" function for measuring the current data provided by the current sensor on pin 34 of the development board, "emon.apparentPower" function to calculate the power from the voltage and current data obtained and the power consumption is measured by applying the formula shown in the figure wich is " $\mathrm{kWh}=\mathrm{kWh}+$ emon.apparentPower $+($ millis ()$-$ lastmillis $) / 3600000000.0$ ". All the values mention above are listed on the LCD display of the system and on the serial monitor by using the function "serial.print" for each value.

\section{EnergylMonitor emon;}

\section{\#define vCalibration 106.8

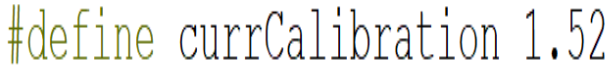

Figure 6. Energy measuring calibration code.

For calibrating the sensor used we have implemented two variables, vCalibration and currCalibration used to software calibrate the voltage and current sensor.

\subsection{Blynk application}

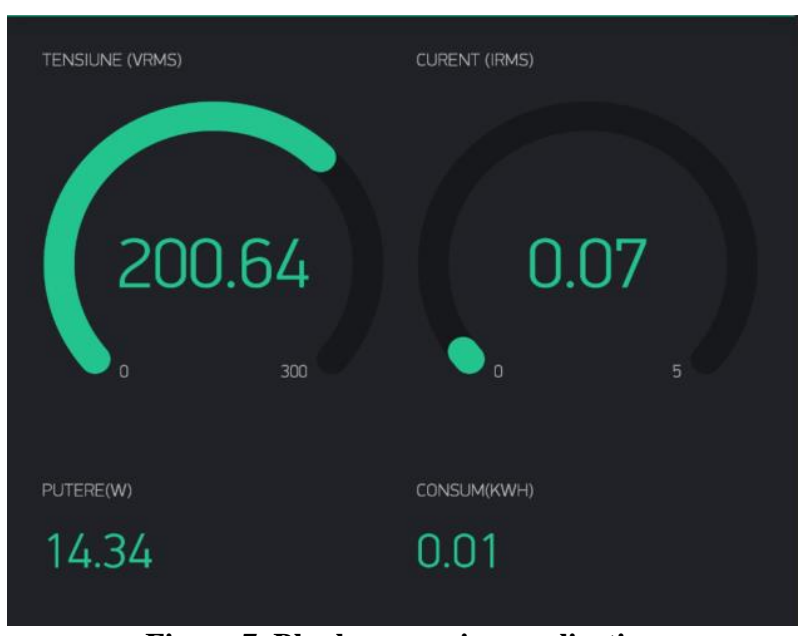

Figure 7. Blynk measuring application.

Using the Blynk application we have made an intuitive application that shows the user the measured values of the electrical consumer has shown in Figure 7.

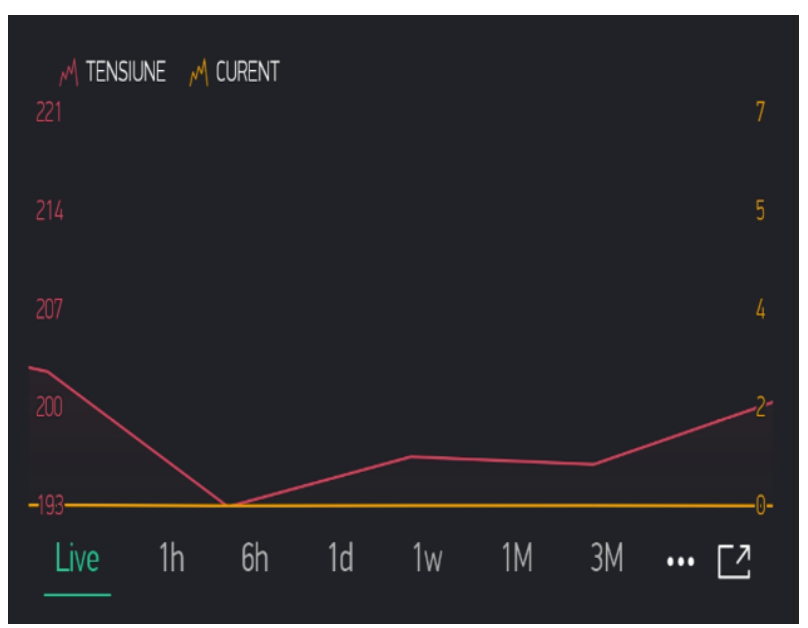

Figure 7. Blynk measuring application graph. 
The Blynk application allows the implementation of a graph function that is capable to store the values measured by the system up to a period of 12 months and the data can also be exported in a .CSV format for further analysis or implementation.

\section{MEASURING COMPARISONS}

For testing the measurement system, we have used a 10W LED light bulb which his sole purpose is to represent the measured electrical consumer. Along with the system we have used an ANENG AN9002 True RMS multimeter for comparing the values obtained by the system. The sequential measurement values are shown below.

Table 1. System measurements comparisons 1.

\begin{tabular}{|l|c|c|}
\hline MU & System & AN9002 \\
\hline Voltage & $200.64 \mathrm{~V}$ & $200.5 \mathrm{~V}$ \\
\hline Current & $0.075 \mathrm{~A}$ & $0.073 \mathrm{~A}$ \\
\hline
\end{tabular}

Table 2. System measurements comparisons 2.

\begin{tabular}{|l|c|c|}
\hline MU & System & AN9002 \\
\hline Voltage & $224.15 \mathrm{~V}$ & $224.4 \mathrm{~V}$ \\
\hline Current & $0.072 \mathrm{~A}$ & $0.076 \mathrm{~A}$ \\
\hline
\end{tabular}

Table 3. System measurements comparisons 3.

\begin{tabular}{|l|c|c|}
\hline MU & System & AN9002 \\
\hline Voltage & $228.34 \mathrm{~V}$ & $228.5 \mathrm{~V}$ \\
\hline Current & $0.075 \mathrm{~A}$ & $0.078 \mathrm{~A}$ \\
\hline
\end{tabular}

Table 4. System measurements comparisons 4.

\begin{tabular}{|l|c|c|}
\hline MU & System & AN9002 \\
\hline Voltage & $226.15 \mathrm{~V}$ & $225.9 \mathrm{~V}$ \\
\hline Current & $0.078 \mathrm{~A}$ & $0.079 \mathrm{~A}$ \\
\hline
\end{tabular}

\section{CONCLUSIONS}

This paper demonstrates the development of a system that can measure both the mains voltage and the current used by a consumer. The ZMPT101B voltage sensor offers very good accuracy due to the possibility of calibrating it either from the existing potentiometer on the sensor or from the software program and is able to measure a voltage up to $250 \mathrm{~V}$. The current sensor SCT-013-030 allows the system to measure a current / consumer up to $30 \mathrm{~A}$, this is quite accurate due to the possibility of calibration in the software program of the system. The ESP32 development board is a good choice for this IoT project due to its technical specifications (18 ADC channels with a 12-bit resolution and support for $\mathrm{Wi}-\mathrm{Fi}$ $802.11 \mathrm{~b} / \mathrm{g} / \mathrm{n}$ connectivity). The system measures the voltage (U), the current (I) consumed by the bulb, the power consumed $(\mathrm{W})$ and the consumption / hour $(\mathrm{kWh})$.
The measured values are either displayed on the system's LCD display or on the Blynk application by connecting the system to the internet using Wi-Fi technology. The application has a graph that records the measured electricity values over a period of 12 months and this graph can be exported in CSV format (comma separated values file) for further analysis or implementation.

\section{REFERENCES}

[1] Inginerie electrica moderna, Dorina Popovici, Horia Andrei, Costin Cepisca. Editura Electra 2004; ISBN: 973-8067-87-1, ISBN vol. II: 973-7728-17-3.

[2] The Measurement, Instrumentation and Sensors Handbook (Electrical Engineering Handbook), John G. Webster, CRC Press; 1st edition (December 29, 1998); ISBN-10:0849383471, ISBN-13:9780849383472 .

[3] E. Diaconu, "Controlul sistemelor electronice", Targoviste, Romania, Valahia University Press, ISBN 978-606-603-170-7.

[4] V. Ion, A.C. Gheorghe, E. Diaconu, "Electrical Characteristics Measuring Device for Security Systems", The Scientific Bulletin of Electrical Engineering Faculty 21(1):60-63, April 2021, DOI: 10.2478/sbeef-2021-0012.

[5] V. Ion, H. Andrei, E. Diaconu, M.N. Ardeleanu, A.C. Gheorghe, "The analysis of the electrical characteristics for an anti-theft alarm system", 13th International Conference on Electronics, Computers and Artificial Intelligence (ECAI), July 2021, DOI: 10.1109/ECAI52376.2021.9515183.

[6] V. Ion, H. Andrei, E. Diaconu, M.N. Ardeleanu, A.C. Gheorghe, "Electrical characteristics analysis of video surveillance systems", 13th International Conference on Electronics, Computers and Artificial Intelligence (ECAI), July 2021, DOI: 10.1109/ECAI52376.2021.9515070.

[7] Cepisca, C, Seritan, G, Cepisca, C,I, Grigorescu, S.D, - Digital Sampling Method in the Measurements of Electrical Power and Energy - In: Proceedings of the 9th WSEAS Int. Conf. on Mathematical Methods and Computational Techniques in Electrical Engineering, Book Series Title: Electrical and Computer Engineering, pp. 45-49, Arcachon, France, October 13-15, WOS000254019000008 